\title{
A “ONDA” FUNÇÃO SOCIAL DA EMPRESA E SUA IMBRICAÇÃO COM O DIREITO FUNDAMENTAL À SEGURANÇA JURÍDICA NO BRASIL
}

\section{THE "WAVE" SOCIAL FUNCTION OF THE COMPANIES AND ITS IMPLICATION WITH THE FUNDAMENTAL RIGHT TO THE JURIDICAL SAFETY'S ON BRAZIL}

\author{
Martha Asunción Enriques Prado" \\ Aldimar Alves V. Silva"
}

\begin{abstract}
Resumo: Visa integrar as perspectivas dos interesses econômicos das empresas com as expectativas de efetivação dos direitos sociais a partir do projeto político do Estado Democrático de Direito. Situa historicamente o Estado contemporâneo nacional, sincronizando as ideologias econômicas correspondentes; traça o perfil constitucional da economia e do Estado, assentando seu vetor social. Revela a insuficiência dogmática do princípio da função social da empresa e desenvolve sua imbricação com a problemática da segurança jurídica; tratando-a como direito fundamental e afastando sua ontologia dos interesses ideológicos. Da distinção vislumbra duas formas pragmáticas de se minimizar a insegurança jurídica existente no âmbito da função social da empresa.
\end{abstract}

Palavras-chave: função social e empresa, estado, modernidade, desenvolvimento social, desenvolvimento econômico e segurança jurídica.

\begin{abstract}
It seeks to integrate the perspectives of the economic interests of the companies with the expectations of realization of the social rights, starting from the political project of the Democratic State of Right. Think the national contemporary State historically, synchronizing the corresponding economic ideologies; make the constitutional profile of the economy and of the State, seating its social vector. Its reveals the dogmatic inadequacy of the beginning of the social function of the company and it develops its implication with the juridical safety's problem; treating her as fundamental right and moving away its ontology of the ideological interests. From that distinction shimmers two pragmatic forms of minimizing the existent juridical insecurity in the ambit of the social function of the company.
\end{abstract}

Keywords: Social function and company. State. Modernity. Social development. Economic development. Juridical safety.

Doutora pela PUC/SP. Professora titular do programa de mestrado em Direito Negocial da Universidade Estadual de Londrina (UEL).

Graduado pela Universidade Estadual de Londrina (UEL). Especialista em Direito do Estado. Mestrando em Direito Negocial na UEL. 


\section{CONSIDERAÇÕES PRELIMINARES}

O Estado Contemporâneo, de cunho moderno ou pós-moderno ${ }^{1}$, mantém compromisso com a democracia econômica e social. Nada de diferente se constata no sistema constitucional brasileiro, porque também insere essa forma de equalização política em face ao sistema econômico capitalista então adotado.

O sistema capitalista, do modo como se encontra previsto no Estado Democrático de Direito instituído no Brasil em 1988, vincula-se a um programa constitucional de desenvolvimento econômico que prega a conjugação de esforços entre iniciativa privada e iniciativa estatal para a construção de uma economia nacional sólida e socialmente ética. Onde a racionalidade econômica estrita "não pode deixar de envolver-se com valorações, símbolos e imagens coletivas, toda uma gama, enfim, de intangíveis e inefáveis que escapam ao domínio da pura razão econômica”. (MARQUES, 1996, p. 23-24).

A Constituição Federal não compartimentou as funções social e econômica, atribuindo aquela ao Estado e esta à iniciativa privada. Criou sim um sistema misto, onde o Estado e a Empresa possuem funções econômico-sociais. Por ser assim, importa afirmar que ao garantir ao capital a liberdade de empresa, vinculaa ao conceito social de livre iniciativa, ou seja: direito de empreendimento conjugado a deveres, entre eles, de preservação do meio ambiente, respeito ao consumidor, respeito ao trabalhador. Aliás, nesse sentido Isabel Vaz (1992, p. 348) faz consideração bastante substanciosa:

A qualquer membro da sociedade seriam reconhecidos poderes, traduzidos em direitos, de exigir, tanto do Estado quanto dos sujeitos econômicos privados, que the assegurem a "existência digna" [...] a concretização daquele direito deveria operar-se, primordialmente, no plano da empresas.

Há, pois, um compromisso assumido pelo Estado, como há uma funçãotarefa atribuída à empresa, ambos juridicamente delineados; o que traz ao cenário o Direito como instrumento de manutenção da ordem e perseguição dos fins estabelecidos.

\footnotetext{
${ }^{1}$ Apresenta-se os vocábulos “moderno" e "pós-moderno" com o propósito de se destacar que independentemente da posição que se tome em face desse embate filosófico, o Estado contemporâneo, "moderno" ou "pós-moderno", tem compromisso com a democracia econômica e social.
} 
A onda função social da empresa e sua imbricação com o direito fundamental da segurança...

\section{FUNÇÃO SOCIAL DO ESTADO E FUNCÃO SOCIAL DA EMPRESA NO ESTADO CONTEMPORÂNEO BRASILEIRO}

O perfil de estado democrático de direito ${ }^{2}$ que o Brasil ostenta, dentre os vários sentidos que isso representa na ordem jurídica, traz implícita a afirmação de Willis Santiago, como "fórmula política que representa a síntese em que se supera, dialeticamente, estado liberal de direito e Welfare State, de um lado, e, de outro, estado social e socialista de direito.” (GUERRA FILHO, 1997, p. 29).

Visto o Estado brasileiro contemporâneo dessa forma, como um estágio de superação e síntese dos dois sistemas anteriores; e, compulsando-se o texto constitucional em busca desse ideário democrático encontra-se um Estado voltado à participação nos problemas da sociedade. Da mesma forma, se constata uma ação estatal ativa no sentido de promover a participação de todos na resolução dos problemas sociais.

A função social do estado, democrático de direito, seguindo a noção de síntese e superação acima referida é decorrência necessária da sua própria institucionalização; ou seja, possui função instrumental para com a democracia e o direito, e, conseqüentemente, compromisso com a efetivação do bem comum.

Por outro lado, a função social da empresa, na seara do Estado Democrático de Direito, funciona como instrumento engendrado pela própria Constituição, para atuar em sintonia com a função social do Estado. Porque a função meramente econômica da Empresa, típica do liberalismo econômico ou do Welfare State se atualiza juntamente com a função social do Estado ${ }^{3}$.

\subsection{Definicão da função social do estado em uma sociedade em desenvolvimento não-gradual}

As estruturas chaves antes referidas são o Estado e a Economia. Ao se considerar que ambas possuem existência histórica recente, constata-se que não apresentam mais de duzentos anos e se identificam com as instituições da modernidade. Esta, por sua vez, representa o momento histórico que a humanidade passa a viver um circuito frenético e acelerado de transformações.

É na modernidade que surge o estado, liberal inicialmente, e democrático de direito na seqüência. Confira seu fundo ideológico nas palavras de Bauman:

${ }^{2}$ Ver artigo 1. ${ }^{-}$da Constituição Federal de 1988.

${ }^{3} \mathrm{O}$ Estado contemporâneo brasileiro vive a conjugação dessas teleologias, no sentido de que um liberalismo econômico revisitado e o Estado Democrático de Direito determinem a efetivação das 'promessas sociais da modernidade'. 
A convicção moderna de que a sociedade não precisa ser como é, que pode ser melhorada, tornou cada caso de infelicidade individual e grupal um desafio, um problema a atacar [...] para uma mentalidade ensinada a tratar a sociedade como um projeto inacabado que cabia aos administradores completar, a pobreza era uma abominação. (BAUMAN, 1999, p. 272).

Praticamente todas as nações-estado do ocidente seguiram a dinâmica da modernidade, mas apenas algumas conseguiram alcançar progresso econômico conjugado com desenvolvimento social. De modo eficiente isso se deu nos países centrais $^{4}$, onde, hoje, o poder político de tais Estados encontra-se toleravelmente equilibrado com o poder econômico do capital privado. Dessa forma, a estabilidade social existente decorre exatamente da harmonização entre poder político estatal e poder econômico.

Nos países periféricos e semi-periféricos ${ }^{5}$ há um déficit de poder econômico interno, de maneira que o poder político ao buscar suprir essa deficiência, acaba por instaurar um desequilíbrio ainda maior entre as forças sociais. Isso porque, a abertura incondicionada do espaço interno ao capital internacional gera submissão econômica; e, esse poder econômico externo, internalizado, passa a ser o contraponto do poder político interno.

Desse modo, sem haver equilíbrio nos moldes dos países centrais ${ }^{6}$, em países como o Brasil, acaba preponderando o interesse do poder econômico internacional em face do poder político nacional. Fato determinante para que, a decisão política privilegie o poder econômico internacional ${ }^{7}$. Apenas posteriormente, por força de conseqüência e indiretamente, dá-se prioridade aos interesses econômicos

4 O uso das expressões "países centrais, países periféricos e países semi-periféricos" é amplamente utilizado pelos estudiosos dos fenômenos da globalização mundial. Em visão estritamente econômica atribui-se o primeiro título a países altamente desenvolvidos economicamente e dotados de influente poder político no cenário mundial.

${ }^{5}$ Seguindo as premissas da nota explicativa anterior, tem-se que os "países periféricos e países semi-periféricos" são aqueles dotados de baixo poderio econômico ou que se encontram em vias de desenvolvimento econômico.

${ }^{6}$ A globalização, longe de seu consensual, é, como veremos, um vasto e intenso campo de conflitos entre grupos sociais, Estados e interesses hegemônicos, por um lado, e grupos sociais, Estados e interesses subalternos, por outro; e mesmo no interior do campo hegemônico há divisões mais ou menos significativas. (SANTOS, 2002, p. 27; Grifo nosso).

7 As firmas de negócios, especialmente as corporações multinacionais, podem controlar imenso poder econômico, e ter a capacidade de influenciar sistemas políticos em seus países-base e em outros lugares. (GIDDENS, 1991, p. 75). 
A onda função social da empresa e sua imbricação com o direito fundamental da segurança...

internos; e somente cumpridos esses estágios de prioridades o poder político passa a discutir os demais interesses do estado-nação.

A todo interesse que seja contrário ou irrelevante ao poder econômico, internacional ou interno, é reservado espaço restrito de deliberação.

De qualquer forma, o estado-nação, para cumprir minimamente a sua função de Estado precisa atender a interesses de alteridade; alheios, contrários ou contraditórios à teleologia do poder econômico. Entretanto, precisa atender também aos anseios e necessidades sociais do povo.

Nesse contexto, o Estado Contemporâneo Brasileiro enquadra-se dentre aqueles que agem modesta e sutilmente no âmbito social, tanto em sentido de manutenção quanto de implantação de políticas sociais ou de redistribuição de riquezas. Há incontestável deficiência na programação de projetos de longo prazo e necessidade de aprofundar e desenvolver políticas de suprimento imediato.

No entanto, o que ocorre na administração dos estados periféricos é que o governo se vê obrigado a coordenar ações que compatibilizem os interesses daqueles três âmbitos ${ }^{8}$; tarefa hercúlea não apenas em virtude das teleologias conflitantes dos diversos sistemas, mas principalmente por força da interferência do poder econômico nos âmbitos de decisão política.

Essa disputa de poder, no entanto, não é meramente fática, já que entra para compor as regras do jogo político também as regras do Direito; ou seja, tanto o poder político quanto o poder econômico possuem uma configuração jurídica na ordem interna do estado-nação. Sendo a Constituição Federal quem inaugura normas jurídicas que, delineiam os pontos de ação e interação entre o poder econômico e o poder político.

O Direito estabelece um padrão de comportamento ao Estado, assim como o faz em relação aos particulares: no âmbito do Estado, o poder político, pertence ao governo; no âmbito privado, o poder econômico, pertence ao particular nos diversos setores da economia. Isso em perspectiva conceitual abstracionista, porque não há como negar que o poder econômico exerce influência no governo e o poder político interfere na economia.

$\mathrm{Na}$ medida em que essas interferências recíprocas seguem os limites traçados na Constituição Federal, a ordem econômica e a ordem política não correm riscos; mas, toda vez que o governo age em desacordo com a Constituição ou outras regras de Direito, privilegiando interesse público secundário ou interesse econômico de fato, põe em risco a confiança no ordenamento jurídico.

${ }^{8}$ Interesses econômicos internacionais, interesses econômicos internos e interesses sociais. 
Desse modo, nos países periféricos e semi-periféricos tem sido uma constante as decisões governamentais que contrariam as normas jurídicas em função das regras ditadas pelo poder econômico ${ }^{9}$. E o prejuízo que daí advém não atinge apenas aos interesses preteridos, mas também aos privilegiados, haja vista que há permanente indefinição e incerteza dos rumos e direções que serão adotadas a cada legislatura, sem adentrar nas minúcias da dinâmica legiferante. Isso porque, o poder político tem pertencido cada vez mais ao governo, no âmbito do executivo, do que ao Estado como expressão de uma identidade nacional.

Constata-se que, a discussão sobre a função social do Estado pressupõe uma prévia compreensão das forças políticas dominantes na base territorial considerada.

Tão importante quanto refletir sobre questões como i) necessidadeprescindibilidade do Estado em face à solução de graves problemas sociais, ii) expressão dos valores democráticos em sincronia e correspondência entre destinatários e detentores do poder, iii) realização do bem comum, e, iv) a função social, em sentido estrito, como dever de implementação em favor de todos de uma administração saudável, de políticas vocacionadas à efetivação dos direitos humanos e da solidariedade; é questionar sobre a sua eficácia, como garantidor dos compromissos constitucionais e a sua submissão às ordens da sociedade em geral, ditadas pela Constituição e outros diplomas jurídicos.

Nesse cenário, o quanto se constata em países envolvidos em processo de desenvolvimento não-gradual é que há uma postura estatal voltada ao atendimento paliativo e situacional do primeiro grupo de interesses conjugado com o reiterativo descumprimento do segundo. Esse trabalho inverso, no entanto, gera um círculo vicioso de descumprimento parcial nos dois âmbitos; já que o normal seria desonerar-se dos deveres funcionais primeiramente para que então, conseqüentemente, atingisse as metas e fins que lhe são inerentes.

Assim, o Estado que não consegue cumprir com a sua função social, nem com seus deveres instrumentais imanentes, põe em risco a legitimidade de seus atos e a confiabilidade em suas instituições.

Como a questão mais proeminente do estado contemporâneo nos países periféricos, em desenvolvimento, é a conciliação dos interesses econômicos e sociais, optou-se por trazer à tona uma representação jurídico-dogmática para dar seqüência às observações jus-sociológicas nessa problemática. Parte-se, portanto, a considerar o comportamento estatal em relação à empresa; especificamente no que concerne à sua função social.

${ }^{9} \mathrm{O}$ poder econômico, por não ser dotado de centro decisório - estatal - só pode interferir no poder político através do próprio sistema político. 
A onda função social da empresa e sua imbricação com o direito fundamental da segurança...

\subsection{Indefinição jus-positiva da função social da empresa: uma aproximação crítica}

Por mais que se pretenda abandonar a dicotomia clássica da distinção entre direito privado e direito público, isso não se faz sem algum esforço no estudo de alguns institutos, como o da empresa, por exemplo. Tendo-se que, inclusive, partir de um estudo compartimentado para depois promover a unificação conceitual.

Em uma perspectiva privatística, ou seja, a função social da empresa vista a partir das relações jurídicas internas travadas entre os sujeitos responsáveis pelo desempenho da atividade econômica cita-se os Artigos 116, parágrafo único e 154 da Lei n. 6.404/76, assim como o Art. 116, $§ 7 . . a$ da antiga Lei das S/A, Decreto-Lei 2.627/40. De onde não se consegue extrair mais sentido do que o simples dever do administrador ou acionista controlador com os demais acionistas ${ }^{10}$, empregados e comunidade em um sentido amplo, genérico e abstrato. Esse mesmo dever fora instituído aos administradores das sociedades limitadas por força do art. 18 do Decreto 3.078/19, o qual previa aplicação subsidiária da Lei das Sociedades Anônimas.

Mesmo diante dessa insuficiência normativa e sob a vigência da Constituição Federal de 67/69, Fabio Konder Comparato (1983) afirmava que:

a instituição do Estado social impôs [...] duas conseqüências jurídicas da maior importância para a organização das empresas [...] já não se funda na propriedade dos meios de produção, mas na qualidade dos objetivos visados pelo agente; sendo que a ordem jurídica assina aos particulares e, especialmente aos empresários, a realização obrigatória de objetivos sociais. (p. 296).

Essa interpretação acentuada e visionária inspirou pouco, no entanto, ao legislador do atual Código Civil.

O Código Civil, ao unificar o Direito Comercial e o Direito Civil, não tratou expressamente sobre a questão da função social da empresa; tudo que de lá se consegue extrair é uma aproximação dimensionada analogicamente com a função social da propriedade e a função social do contrato. ${ }^{11}$

${ }^{10}$ Fábio Konder Comparato (1983) acresce a esses ‘interesses intra-empresariais' os 'extraempresariais', “eles dizem respeito à comunidade local, regional ou nacional, em que se insere a empresa”. (p. 296).

${ }^{11}$ Ressalta-se que a própria aplicação subsidiária das normas contidas na Lei das Sociedades Anônimas foi expressamente suprimida pelo Art. 1.053, parágrafo único, do Código Civil vigente. 
Da mesma forma, como ocorre nessas leis de direito privado, não se encontra qualquer referência explícita à locução função social da empresa na Constituição Federal ou outro diploma tido como instituidor de normas de direito público. Mas, nesse âmbito, ao contrário do que ocorre naquele, há possibilidade de uma construção interpretativa, do conceito de função social da empresa, que extrapole os limites internos da companhia, sociedade ou comerciante individual.

Nesse sentido, a partir dos princípios fundamentais individuais ou coletivos e princípios gerais da ordem econômica insertos na Constituição Federal de 1988 é possível construir um conceito de função social da empresa que, oriente toda a "atividade econômica organizada para a produção ou a circulação de bens ou de serviços"12 à consecução de fins, concretização de valores e implementação de garantias extravagantes aos interesses imediatos da atividade empresária.

Fortemente dependente de concretização legislativa e de instrumentos fiscalizatórios ou de políticas governamentais, a função social da empresa não tem alcançado resultados práticos significados em garantias sociais como a proteção do meio-ambiente, do trabalho e do consumidor, nesse último aspecto dá-se ênfase especial às relações financeiras; ou tarefas primordiais como a redução das desigualdades regionais e sociais e tratamento favorecido às pequenas empresas.

$\mathrm{Na}$ locução função social da empresa pôde-se perceber a significativa indeterminação jurídico-positiva do conceito. Porque a união de perspectivas, tirante a questão dogmática de que todas as normas infra-constitucionais devem seguir as orientações da ordem econômica e constitucionais em geral, decorre a constatação crítica de que há uma omissão legislativa renitente sobre um assunto de relevante interesse social, o que acaba gerando insegurança jurídica tanto à empresa quanto ao cidadão.

\section{A INDETERMINAÇÃO JURÍDICA DA FUNÇÃO SOCIAL DA EMPRESA E A CRISE CONCEITUAL E PARADIGMÁTICA DA SEGURANÇA JURÍDICA NO ESTADO CONTEMPORÂNEO}

Não há um conceito pronto e definitivo de segurança jurídica, dotado de validade universal; assim como não o há livre de ideologias ou teorias políticas e sociológicas sobre a própria função do Direito na sociedade. Sendo assim, trata-se de um conceito historicamente cambiante. Durante o estado absolutista confundia-se com a capacidade normatizadora e legiferante do Estado; no Estado Liberal, confundia-se com o dever irrestrito de aplicabilidade das normas a partir

${ }^{12}$ Artigo 966 do Código Civil de 2002, caput, parcialmente. 
A onda função social da empresa e sua imbricação com o direito fundamental da segurança...

de interpretação hermética ${ }^{13}$; e, no estado democrático de direito a segurança jurídica surge como reação normal e concomitante com as teorias contrárias aos regimes anteriores.

Se por um lado a segurança jurídica era elemento forte de justificação das ideologias dos Estados Absolutistas e Liberais, por outro ela passa a ter que brigar por espaço entre os elementos ideológicos do estado democrático de direito.

Considerando que a feição socializante do Estado Democrático de Direito se funda na reorganização do capitalismo em busca da valorização dos direitos das massas, a segurança jurídica só se justifica se for vista como direito fundamental que pró́ba o retrocesso social e de garantia dos direitos fundamentais ${ }^{14}$.

Em perspectiva extra-dogmática, pode-se afirmar que a certeza do direito é objetiva e a certeza no direito é subjetiva. A segurança jurídica, por sua vez, é a conformação técnica interna do sistema jurídico em relação a essas duas formas de se encarar o fenômeno do Direito em sua dinâmica social. Ela determina o quantum de uma e da outra. Cada sistema, geográfica e historicamente posicionado, com sua lógica interna de normatizar o mundo da vida, propicia a segurança jurídica proporcionalmente, ou proporcionalmente inversa, ao "quantum de determinabilidade" que pretende instaurar, em face de sua tarefa prévia de garantir a manutenção de um dado status quo.

A previsibilidade que o sistema normativo em sentido estrito proporciona não é, e não pode ser, incompatível com o sistema normativo pautado em valores normatizados.

Se a previsibilidade é por sua própria essência oscilante, em uma sociedade pautada em valores, mesmo que parcialmente, e em desenvolvimento nãogradual ${ }^{15}$, ela se torna um paradoxo: i) há de ser previsível que os interesses

${ }^{13}$ Nesse sentido, confira o seguinte trecho: "o ingresso no exercício do poder estatal, pela nova classe, emergida da economia liberal, precisavam segurança jurídica, requeriam ordem nas relações sociais, previsão normativa da conduta interindividual. o direito posto pelas constituições e pelas codificações do direito privado exprime a relativa estática no processo social, no século XIX”. (VILANOVA, 2003, p. 465).

${ }^{14}$ Como observa Ingo Wolfgang Sarlet em "A eficácia do direito fundamental à segurança jurídica: dignidade da pessoa humana, direitos fundamentais e proibição de retrocesso social no direito constitucional brasileiro".

${ }^{15}$ Lourival Vilanova, no artigo "Proteção jurisdicional dos direitos numa sociedade em desenvolvimento" promove um estudo profícuo e multidisciplinar sobre o Direito e sua tarefa ativa na sociedade em desenvolvimento não gradual. Foca o Estado brasileiro e a função determinante do Poder Judiciário na realização dos direitos sociais. 
sociais da maioria-descapitalizada será perseguido; ii) há de ser previsível que os interesses da minoria-capitalizada serão garantidos e preservados.

Necessário se faz distinguir dois pontos. No Estado em desenvolvimento não-gradual há duas lógicas internas complementares: i) uma da maioria em suas relações internas, que, como a das minorias, deverá ser preservada e garantida (relações pautadas no critério das normas em sentido estrito: $A \rightarrow B)^{16}$; e, ii) a outra, que tem o compromisso de coordenar os interesses macro e, em geral antagônicos, entre maioria e minoria.

Pode-se isolar artificialmente em $i$ a figura dos cidadãos comuns e em ii a figura da empresa, isoladamente, onde existe previsibilidade em grau considerável; já que em grande escala existem regras bem definidas sobre as relações individualizáveis entre os cidadãos e sobre as relações estritas da atividade empresarial. Tanto lá quanto cá, haverá uma gama de regras determinando que para toda ação $A$, sempre haverá uma conseqüência $B$ diretamente correspondente.

Essa capacidade de prever condutas e resultados passa a sofrer oscilações sérias quando se propõe a considerar os interesses da maioria em face aos interesses da minoria; não só porque os interesses são ontologicamente antagônicos, mas especialmente porque são utilizadas técnicas jurídicas diferentes na normatização dos dois grupos.

O problema ontológico é resolvido ainda em sede constituinte, haja vista que a opção clara pelo estado democrático de direito, em relação à também clara opção pelo sistema econômico capitalista, não deixa dúvidas de que os interesses culturalmente antagônicos terão que concorrer complementarmente. Assim, considerando-se a horizontalidade no desenvolvimento, não-gradual ou progressista, dos dois grupos, percebe-se uma vocação constitucional determinando a interferência pró-ativa do Estado, não em verticalizar o desenvolvimento capitalista, mas de minimamente aproximar as linhas que contêm anseios exclusivamente econômicos e sociais. Esclarece-se, ainda, que em virtude da unidirecionalidade econômica, clássica ou neoliberal, toda ação do Estado, tendente à efetivação dos anseios dos grupos sociais, é em princípio contrária aos interesses do grupo econômico.

${ }^{16}$ A norma primária e a norma secundária contêm, cada qual, uma hipótese e uma conseqüência; lá a descrição de um fato lícito que gera a conseqüência relação jurídica, aqui, a descrição de um fato ilícito que gera a conseqüência relação jurídica sancionatória. A articulação interna das normas se dá através de duas proposições condicionais ou implicacionais. No plano formal, se $\mathrm{H}$, então C; e, no plano fáctico: se se dá o fato, então advém o efeito. (VILANOVA, 2000, p. 77-78). 
A onda função social da empresa e sua imbricação com o direito fundamental da segurança...

A questão da técnica jurídico-legislativa abre outra perspectiva, ou seja, a maioria das normas que garantem direitos ou impõem direitos à empresa funcionalizam-se a partir de regras estritas no sentido $A \rightarrow B$, onde para todo antecedente $\mathrm{A}$ haverá sempre um conseqüente $\mathrm{B}$, conforme explicado acima. Os interesses do grupo econômico se manifestam quase sempre pela manutenção do status quo, e, ainda quando o têm como projeto, exigem a sua instituição jurídica no critério legislativo acima demonstrado.

Sempre que dada ação estatal tendente à alteração do status quo, não solicitada, ou quando pretendida, não verta normas no sentido $A \rightarrow B$, se reverte em insegurança jurídica.

Do outro lado, no grupo dos interesses sociais, toda perseguição, que normalmente não está garantida na fórmula $A \rightarrow B$, não possui grau eficaz gerador de segurança jurídica.

As relações que envolvem o grupo econômico e o grupo social de modo recíproco e bi-reflexivo, em seus interesses culturalmente antagônicos, são incapazes de gerar segurança jurídica a ambos.

Conceitualmente, o grupo econômico possui mais garantias concretizadas juridicamente. Então, quando o grupo social e o grupo econômico se encontram conflitualmente, em inter-relação concreta, o grupo econômico está aparentemente mais paramentado, em perspectiva ideológica do ordenamento de feição liberal, renitente por sua força-tradição, para fazer valer seus interesses; já que goza da eficácia jurídica das normas $\mathrm{A} \rightarrow \mathrm{B}$. Enquanto ao grupo social é dada a força de eficácia da baixa densidade conceitual dos valores.

Há que se estabelecer uma gradação-válida de previsibilidade entre o grupo de normas sociais e o grupo de normas econômicas. E isso poderá ser chamado de segurança jurídica; mesmo que minimamente, na medida em que o sistema jurídico propicie normativamente, uma perspectiva da ponderação através de valores.

Reiniciando-se do ponto em que a Constituição Federal é instrumento jurídico, estruturada por meio de regras e princípios jurídicos, e que todas as suas normas, inclusive aquelas que vertem valores, são normas jurídicas; então, também sobre essas, é imperativo que se alcance segurança jurídica. Não a partir de paradigma condizente com as propostas do Estado liberal clássico, mas através de uma perspectiva diferente, mais aberta e funcional, condizente com os problemas do estado contemporâneo e coerente com o Estado Democrático de Direito Nacional; já que "na história do mundo atual, é sobretudo o Estado que tem condições de assumir a empresa do desenvolvimento global, integral, racionalizado". (VILANOVA, 2003, p. 469). 
Aplicando-se essas considerações sobre a segurança jurídica à função social da empresa chega-se a duas conclusões: a função social da empresa causa insegurança jurídica ao grupo econômico porque não está prevista no ordenamento através da fómula $\mathrm{A} \rightarrow \mathrm{B}$; e, a função social da empresa não causa segurança jurídica ao grupo social porque os agentes jurídicos ainda não alcançaram um meio adequado de firmar entendimentos sólidos sobre conteúdos normativos implícitos e cambiantes.

Uma solução de cunho legislativo poderia resolver o problema nas duas bases, ou seja, o empresário e a sociedade galgariam confiança na função social da empresa através da segurança jurídica em sentido clássico; normas do tipo das regras regulamentando entabuladamente direitos e deveres do empresário e da sociedade. Ressalvando-se que, ainda nessa solução há de se estar consciente de que "o ordenamento total não se há de tomar como o complexo estático de regras já elaboradas, como o direito vertido textual e contextualmente nos códigos e documentos legislativos, mas como regras gerais e atos de concretização". (VILANOVA, 2003, p. 473).

A outra solução, de cunho jurídico-interpretativo, assentada na perspectiva de uma sociedade pautada em princípios, seria a de dotar as normas vertidas como valores, ainda vigentes com baixo grau de eficácia, com maior dinâmica de aplicabilidade; ou seja, dotar a essas normas uma eficácia tal que imprima aplicabilidade tão previsível quanto as outras normas imprimem. Aqui a solução meramente dogmática é impotente, haja vista que apenas a substituição de uma ideologia liberal do progresso pela moderna ideologia do desenvolvimento ${ }^{17}$ seria capaz de gerar paz social nos dois lados dos interesses econômico-sociais. Diagnosticamente, essa via pressupõe um conjunto de ações integradas dos órgãos do poder estatal, com incontestável identidade de propósitos; onde a garantia dos direitos fundamentais, funcionando como leme, venha a gerar previsibilidade, ainda que a contragosto de uma ideologia meramente progressista.

\section{CONSIDERAÇÕES FINAIS}

Partindo do ponto em que na atualidade os Estados, periféricos em especial, enfrentam problemas das mais variadas ordens, percebe-se que a matriz das variadas

${ }^{17}$ É a ideologia do Estado social de direito. Os direitos individuais perdem a preeminência que desfrutavam. O mínimo de Estado cede lugar ao máximo de Estado, com manutenção das estruturas democráticas na democracia em sentido mais estrito, no Estado-do-bem-estar, ou vai até o limite extremo da estatização global. (VILANOVA, 2003, p. 485). 
crises decorrentes é o embate político, que se trava entre interesses econômicos e interesses sociais.

Esse conflito se reflete tanto nos diversos grupos sociais do mundo da vida quanto em sistemas intermediários e puros como Estado, Economia e Direito. E, em cada cenário específico se desmembra, se imiscui, e se dimensiona novos problemas.

Questões como segurança jurídica e função social da empresa, longe de serem problemas estritamente jurídicos, são questões atinentes a diversos setores da sociedade; que influenciam e sofrem influência, no exemplo, de ordem ideológica, conceitual e histórica.

Tal realidade, esboçada especialmente, com o intuito de averiguar que as diferenças existentes entre a segurança jurídica, em sentido clássico, e a função social privatística da empresa; e, o direito fundamental à segurança jurídica e o princípio constitucional implícito da função social da empresa representam mais uma crise ou conflituosidade de interesses, ora pautados em ideologias ressuscitadas, ora pautadas na necessidade jurídica de se fazer valer as propostas positivadas na Constituição.

\section{REFERÊNCIAS}

BAUMAN, Zygmunt. Modernidade e ambivalência. Trad. Marcus Penchel. Rio de Janeiro: J. Zahar, 1999.

COMPARATO. Fábio Konder. O poder de controle na sociedade anônima. 3. ed. rev., atual. e corrigida. Rio de Janeiro: Forense, 1983.

GIDDENS, Anthony. As conseqüências da modernidade. Trad. Raul Filker. São Paulo: Ed. Unesp, 1991.

GUERRA FILHO, Willis Santigo. Autopoiese do direito na sociedade pósmoderna: introdução a uma teoria social sistêmica. Porto Alegre: Livraria do Advogado Editora, 1997.

MARQUES, Hamilton Nonato. Privatização e qualidade dos serviços de infraestrutura: controle social e participação do consumidor. Rio de Janeiro: IPEA, 1996. Disponível em: 〈http://www.ipea.gov.br/pub/td/td0426.pdf〉. Acesso em: 25 ago. 2006.

SANTOS, Boaventura de Souza. A globalização e as ciências sociais. 2. ed. São Paulo: Cortez, 2002.

SARLET, Ingo Wolfgang. A eficácia do direito fundamental à segurança jurídica: 
dignidade da pessoa humana, direitos fundamentais e proibição de retrocesso social no direito constitucional brasileiro. Revista Brasileira de Direito Comparado, Rio de Janeiro, n. 28, p. 89-148, 2005.

VAZ, Isabel. Direito econômico das propriedades. Rio de Janeiro: Forense, 1992.

VILANOVA. Lourival. Causalidade e relação no direito. 4. ed. rev. atual. e ampl. São Paulo: Editora Revista dos Tribunais, 2000. . Escritos jurídicos e filosóficos. São Paulo: Axis Mundi, 2003. 